Servicio de publicaciones y difusión científica (SPDC), Universidad de Las Palmas de Gran Canaria, Parque

Científico-Tecnológico, Edificio Polivalente II, C/ Practicante Ignacio Rodríguez, s/n Campus Universitario de Tafira 35017 - Las Palmas de Gran Canaria, Spain.

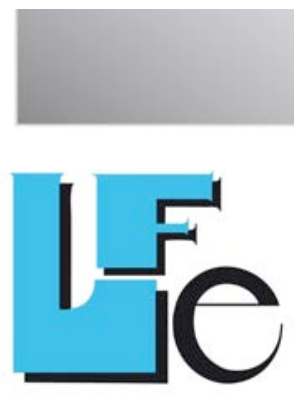

Revista de Lenguas para Fines

Especificos

\section{Revista de lenguas} para fines específicos

\author{
elSSN: $2340-8561$
}

Journal information, indexing and abstracting details, archives, and instructions for submissions:

https://ojsspdc.ulpgc.es/ojs/index.php/LFE/index

\section{Author stance in doctoral dissertations of native and non- native speakers of English: A corpus-based study on epistemic adverbs}

\section{Reyhan Ağçam}

Kahramanmaraş Sut.ư İmam University, School of Foreign Languages.

Article first published online: 25 November 2015.

Article published online with DOI added: 5 April 2016.

Revista de Lenguas para fines específicos is licensed under a Creative Commons ReconocimientoNoComercial-SinObraDerivada 4.0 Internacional License. 


\title{
Author stance in doctoral dissertations of native and non-native speakers of English: A corpus-based study on epistemic adverbs
}

\author{
Reyhan Ağçam ${ }^{1}$ \\ Kahramanmaraş Sütçü İmam University
}

\begin{abstract}
Academic writing is not just about conveying an ideational 'content', it is also about the representation of the self (Hyland, 2002, p. 1092). It allows writers 'to gain credibility by projecting an identity invested with the individual authority, displaying confidence in their evaluations and commitment to their ideas (Hyland, 2002, p. 1092). Our study concentrates on the epistemic adverbs used in conveying author stance in academic English. The Contrastive Interlanguage Analysis (Granger, 1996) was run to three sets of corpora comprising doctoral dissertations written by native and non-native academic authors of English. Epistemic adverbs occurring in the dissertations were identified through a computer programme and their frequencies were separately computed for each corpus. Lastly, a log-likelihood test was administered to see whether there is a statistically significant difference across the groups in concern concerning the use of these adverbs.
\end{abstract}

Keywords: Academic writing, contrastive interlanguage analysis, epistemic adverb, stance

\section{Resumen}

La escritura académica no es solo una manera de expresar contenido ideacional; también es una forma de representación de sí mismo (Hyland, 2002: 1092). Esto permite a los autores 'to gain credibility by projecting an identity invested with the individual authority, displaying confidence in their evaluations and commitment to their ideas (Hyland, 2002, p. 1092). Nuestro estudio se centra en los adverbios epistémicos que se usan para indicar el punto de vista de un autor en inglés académico. El Contrastive Interlanguage Analysis (Granger, 1996) se aplica a tres grupos de corpus de tesis doctorales escritas en inglés por autores nativos y no nativos. Usando medios informáticos, se identificaron los adverbios

\footnotetext{
Corresponding author - Kahramanmaraş Sütçü İmam University, School of Foreign Languages Email: reyhanagcam@gmail.com

"This article was produced from the doctoral dissertation entitled "A Corpus-Based Study on Author Stance in Academic English, submitted to Çukurova University, Turkey"
} 
epistémicos y se computaron sus frecuencias por corpus. Finalmente, se aplicó un test de cociente de probabilidad (log-likelihood test) para comprobar si existían diferencias estadísticamente significativas en los grupos estudiados en cuanto al uso de estos adverbios.

Keywords: escritura académica, contrastive interlanguage analysis, adverbio epistémico adverb, punto de vista

\section{Introduction}

Academic writing is a construction of authorial self as well as the presentation of fact (Scollon, 1994, p. 34). In this vein, Biber et al. (1999, p. 966) propose that speakers and writers mostly express their personal "feelings, attitudes, value judgments, or assessments" when conveying propositional content of their message. Supporting this claim, Hyland (2002, p. 1091) draws our attention to the finding suggested by a large body of research that 'academic prose is not completely impersonal, but that writers gain credibility by projecting an identity invested with individual authority, displaying confidence in their evaluations and commitment to their ideas', which he believes influenced by social and psychological factors. To quote Hyland:

The ways that writers choose to report their research and express their ideas obviously result from a variety of social and psychological factors. Most crucially, however, rhetorical identity is influenced by the writer's background and this becomes more intricate for students familiar with intellectual traditions which may be very different from those practised in English academic contexts. So, while Anglo-American academic conventions encourage a conscious exploitation of authorial identity to manage the reader's awareness of the author's role and viewpoint, L2 writers from other cultures may be reluctant to promote an individual self (Hyland, 2002, p. 1111).

In conveying their stance, researchers tend to exploit stance devices. Hyland (2005, p. 176) contends that these devices allow writers to 'intrude to stamp their personal authority onto their arguments or step back and disguise their involvement'. Conrad and Biber (2000, p. 57) analyse them in three semantic categories as epistemic, attitudinal and style. Biber et al. (1999, p. 854) identify these categories as follows:

Epistemic markers express the speaker's judgment about the certainty, reliability, and limitations of the proposition; they can also comment on the source of the information. Attitude stance adverbials convey the speaker's attitude or value judgment about the proposition's content. Style adverbials, in contrast, describe the manner of speaking.

Not being within the scope of the present study, attitudinal stance and style stance 
devices will not be discussed in detail in this paper. It is considered useful to illustrate epistemic stance devices proposed by Biber (2006, p. 94), as in Table 1.

\begin{tabular}{|c|c|}
\hline ESDs & Examples \\
\hline Adjective + that-clause & $\begin{array}{l}\text { It is evident [that by } 1925 \text { Gandhi had fully worked out his approach } \\
\text { to, and explanation of the text]. }\end{array}$ \\
\hline Adjective + to-clause & These "control failures" are certain [to happen occasionally]. \\
\hline Adverb & Now these schools might possibly be able to afford this special fund. \\
\hline Noun + that-clause & $\begin{array}{l}\text { There's some indication [that prenatal development has an influence } \\
\text { on lifespan development]. }\end{array}$ \\
\hline Verb + that-clause & $\begin{array}{l}\text { Therefore there is no reason to suspect [that the two means are } \\
\text { different]. }\end{array}$ \\
\hline Verb + to-clause & $\begin{array}{l}\text { Our best evidence seems [to suggest that if you control for size, the } \\
\text { more international you are, the less risk you have]. }\end{array}$ \\
\hline
\end{tabular}

Table 1. Epistemic Stance Devices (adapted from Biber, 2006, p. 94).

The present study focused on the use of epistemic adverbs found in the doctoral dissertations written by native, Turkish-speaking and Spanish-speaking academic authors of English. Biber et al. (1999, p. 764) distinguish these adverbs from attitude stance adverbs and style stance adverbs in that they "focus on the truth-value of the proposition commenting on factors such as certainty, reality, sources, limitations, and precision of the proposition". According to them, attitude stance adverbs express the speaker's attitude towards or evaluation of the content and style stance adverbs convey the speaker's comment about the style or form of the utterance, often clarifying how the speaker is speaking or how the utterance should be understood (Ibid). In this particular study, epistemic adverbs are covered in the way they were discussed in a later study conducted by Biber (2006). Namely, they were analysed in two broad categories as certainty adverbs and likelihood adverbs. The following section is intended to discuss some literature including studies with a focus on the use of epistemic stance devices (mainly epistemic adverbs).

\section{Literature Review}

English has a much larger repertoire of epistemic (sentential) adverbs than other European languages, possibly indeed without parallel in other languages of the world (Wierzbicka, 2006, p. 247). She asserts that the cultural concerns reflected in the categories of epistemic adverbs and epistemic verbal phrases are 'essentially the same, and in both cases they can be linked with the post-Lockean emphasis on the limitations of human knowledge, on the need to distinguish knowledge from judgment, and on differentiating between different degrees of assent' (Ibid). Rozumko (2008) concluded that Polish-speaking learners of English have a limited repertoire of English epistemic adverbs when compared to the native speakers. In a 
later study (2012), she explored the inventories of epistemic adverbs in English and Polish assigning a task which required the learners to identify equivalents of these adverbs in two sets. She highlights that the task is not simple as positive speech-act adverbs such as arguably and admittedly do not exist in Polish. Biber (2006) investigated stance adverbs in four major semantic categories (e.g. certainty, likelihood, attitudinal and style) across university registers. He has found that epistemic adverbs, which comprises of certainty and likelihood adverbs, are the most common in the aforementioned semantic categories. He also reports that certainty adverbs (e.g. actually, in fact) are especially common in both spoken and written university registers, and they are 'mostly used by instructors (rather than students) to identify information as factual and beyond dispute' and 'to emphasize the expected activities of students and the instructor' (p. 104). He suggests for likelihood adverbs (e.g. possibly, probably) that 'they are used for similar purposes, indicating events and actions that are likely to occur (or should be done)'. He has concluded that these adverbs are mostly used in office hours to 'suggest actions and events that would be desirable or likely' (p. 105). In a similar study, Kotrč (2012) analysed stance adverbials in the language of press in randomly selected 18 articles published in the newspapers during the General Election 2010 in UK. He has informed that epistemic stance adverbials constituted the dominant majority of all stance adverbials found in the articles, and that certainty adverbials outnumber likelihood ones.

In a corpus-based study, Can (2012) inspected stance adverbs across argumentative essays written by Turkish and American university students. He has revealed that the non-native group used stance adverbs more frequently than the native group, and that the former employed less variety than the latter in their choice of application. Alonso-Almeida (2012) conducted a study on sentential evidential adverbs and authorial stance in English computing articles with a focus on evidentiality in relation to stance. His findings have indicated 'an authorial tendency to use adverbs in the field of clarity and obviousness' (p. 28). He underlines that the devices in concern 'reveal the authors' intention of indicating source/ mode of knowledge, and this is also seen as qualifying the status of the proposition in terms of truthfulness and factuality' (Alonso-Almeida, 2012, p. 28).

In a study on nonverbal markers of modality and evidentiality in the corpus MarENG, 'a maritime English learning tool sponsored by the EU' (35.041 words), Molina (2012) has shown that epistemic adverbs serve two principal functions: (i) to point out the limitations on a proposition, specifying that it takes place in most cases or to a larger degree, and (ii) to show the main signs or qualities of a particular group or class ( $p$. 52). She reports that such epistemic adverbs as apparently, evidently, obviously and truly were not found in the corpus, and that speakers have a predisposition to 
express epistemic modality mostly by the adverbs mainly and probably. As for the epistemic categories, her findings have suggested that adverbs expressing certainty are relatively prevalent when compared to those expressing likelihood meaning.

Adams and Quintana-Toledo (2013) examined stance adverbials in a sub-corpus compiling from research articles written by native speakers of English in the field of law between the years 1998 and 2008. They confined their investigation to the sections of Introduction and Conclusion of the articles in concern. They have found that epistemic stance adverbials were used much more frequently than attitudinal and style adverbials in both sections of the articles, and that certainty adverbials constituted the majority of epistemic stance adverbials. They also note that certainly, clearly, of course and obviously are mostly used 'to mark the author's highest degree of confidence with regard to the truth of a statement whereas perhaps and probably are used 'to signal some level of doubt' (p. 16).

\section{Research Design}

\subsection{Research Questions}

This study was intended to provide answers to the following research questions:

1. Do Turkish-speaking academic authors of English and native academic authors of English significantly differ with respect to the use of epistemic adverbs?

2. Do Spanish-speaking academic authors of English and native academic authors of English significantly differ with respect to the use of epistemic adverbs?

3. Do Turkish-speaking academic authors of English and Spanish-speaking academic authors of English significantly differ with respect to the use of epistemic adverbs?

\subsection{Methodology}

Being corpus-based in design, the present study was intended to investigate author stance in doctoral dissertations of native and non-native academic authors of English. It essentially involved the analysis of three corpora with respect to epistemic adverbs that are frequently reported to occur in the written academic registers in Biber's study (2006). Table 2 outlines these items under two categories as certainty adverbs and likelihood adverbs.

\section{Epistemic Adverbs}




\begin{tabular}{ll}
\hline Certainty & $\begin{array}{l}\text { actually, always, certainly, definitely, indeed, inevitably, in fact, never, of course, } \\
\text { obviously, really, undoubtedly, without doubt, no doubt } \\
\text { apparently, evidently, kind of, in most cases/instances, perhaps, possibly, predictably, } \\
\text { probably, roughly, sort of, maybe }\end{array}$ \\
\hline
\end{tabular}

Table 2. Epistemic Adverbs (Adapted from Biber, 2006, p. 92).

\subsection{Data}

Three sets of corpora including 133 doctoral dissertations produced by Turkishspeaking Academic Authors of English (TAEs, henceforth), Spanish-Speaking Academic Authors of English (SAEs, hereafter) and Native Academic Authors of English (NAEs, henceforth) within the field of English Language Teaching, English Language and Literature, Applied Linguistics and Modern Languages [TACE (Turkish Academic Corpus of English): 48; SACE (Spanish Academic Corpus of English): 43; NACE (Native Academic Corpus of English): 45] were investigated in this study. For practical reasons the corpora were built with the collection of dissertations that were submitted between 2005 and 2012 and available online. Taking into consideration the possibility that those who supervised the dissertations might have influenced the writing process of the sections Abstract, Introduction, Review of Literature, Methodology and References, the sections in concern were excluded from the corpora. Instead, data analysis was made across the sections Findings, Discussion, Conclusion, Pedagogical Implications (Implications to English Language Teaching) and Suggestions for Further Research. Finally, all figures, paraphrases, quotations, tables and titles were excluded from the above-mentioned sections of the dissertations in the corpora. Table 3 illustrates the size of corpora investigated in this study.

\begin{tabular}{lrr}
\hline Corpus & Dissertation $(\mathbf{n})$ & Word $(\mathbf{n})$ \\
\hline TACE & 48 & 675.072 \\
SACE & 43 & 668.256 \\
NACE & 45 & 671.475 \\
\hline Total & 136 & 2.014 .873 \\
\hline
\end{tabular}

Table 3. Corpus Size.

\subsection{Data Analysis}

As the present study involves comparison of three corpora in terms of epistemic adverbs, the Contrastive Interlanguage Analysis (CIA) (Granger, 1996) was adopted for data analysis process, which consisted of six phases. Through the first three 
phases, individual types were identified over each corpus via Wordsmith Tools 6.0, a computer software package developed by Scott (2012). Subsequently, a log likelihood test was applied between the non-native corpora and the native corpus (the fourth and fifth phases), and between the non-native corpora (the sixth phase) to reveal whether they significantly differ in the use of these items.

\section{Results and Discussions}

This section displays findings drawn from the analysis of three corpora including doctoral dissertations produced by TAEs, SAEs and NAEs. Following Biber (2006), a total number of 25 English epistemic adverbs (under two categories as certainty adjectives and likelihood adverbs) were identified over three corpora and their frequencies were measured through WS Tools 6.0. Subsequently, three corpora were analysed into categorical and individual epistemic adverbs to see whether native and non-native academic authors of English significantly differ from each other with respect to these adverbs. It is noteworthy that all items were found at least once in three corpora.

\subsection{Epistemic Adverbs in Three Corpora}

Three sets of corpora were compared with respect to the epistemic adverbs. The overall findings have indicated that fewer types were found in TACE than in NACE and SACE; namely, 22 out of 26 types were seen in TACE whereas only one type was missing in NACE and SACE. Table 5 displays the related frequencies and percentages.

\begin{tabular}{lrrr}
\cline { 2 - 4 } & NACE (L1) & TACE (L2) & SACE (L2) \\
\hline Corpus Size in words & 671.475 & 675.072 & 668.256 \\
Epistemic Adverb (n) & 1315 & 749 & 1496 \\
n per 10.000 & 19.58 & 11.10 & 22.39 \\
T/t ratio (\%) & 0.02 & 0.01 & 0.02 \\
Epistemic Adverb Types (n) & 24 & 22 & 24 \\
\hline \multicolumn{2}{c}{ n= raw frequency of epistemic adverbs } \\
$\quad$ T/t ratio= Type/token ratio; percentage of number of epistemic adverbs (types) in total of words (tokens) \\
$\quad$ in each corpus
\end{tabular}

Table 5. Overall frequency distribution of epistemic adverbs in three corpora.

Considering the frequency distribution of the types across the corpora, it is seen that epistemic adverbs were mostly found in SACE with an approximate frequency of 1500 and least found in TACE occurring less than 750 times, corresponds to an overuse in the former and underused in the latter as opposed to the native corpus. As suggested in Table 5, the frequency ratio of epistemic adverbs in SACE was 
measured 22.39 per 10.000 words, which means 22 in every 10.000 words in the corpus were constituted by these items. They were seen approximately 20 and over 11 times in every 10.000 words in NACE and TACE, respectively. As for the distribution of certainty and likelihood categories in three corpora, it is revealed that certainty adverbs outnumbered likelihood adverbs in all sets, confirming the findings of previous studies (i.e. Biber, 2006; Kotrč, 2012; Molina, 2012; Adams \& Quintana-Toledo, 2013). Figure 1 demonstrates the related distribution across three corpora.

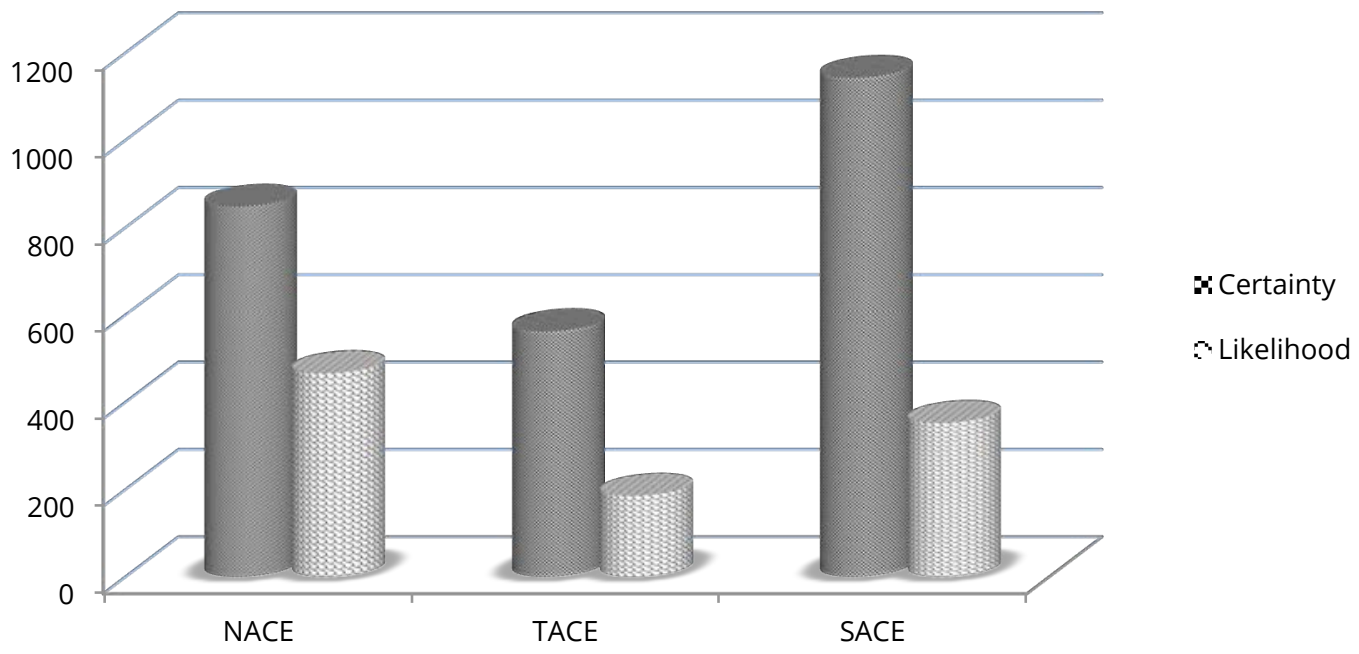

Figure 1. Certainty and likelihood adverbs in three corpora.

Despite displaying similar tendencies in the use of main categories, three corpora remarkably differ from each other in the frequency distribution of epistemic adverbs falling into these categories. Namely, the difference between certainty adverbs and likelihood adverbs in SACE was measured higher than the ones calculated between the categories at stake in NACE and TACE. In general, certainty adverbs were mostly found in SACE with a frequency of 1143 while they were seen 848 and 563 times in NACE and TACE, respectively. That is, they were overused by SAEs and underused by TAEs against NAEs.

Three corpora are mostly alike in the most frequented certainty adverbs. For instance, always is the most frequently used item in NACE and TACE, and second in SACE. Likewise, in fact, which is the most frequented certainty adverb in SACE appears in the third and fourth in the counterpart lists of NACE and TACE, respectively. The following statements were obtained from each corpus to exemplify the items in concern. 
demonstrate empirically the impact that one of these factors is having upon the others. Extracted from $<$ NACE-NU-2011-AB $>$

(2) She always benefited from using proximity to keep students on task and even more from ignoring irrelevant behaviours or warning for disruptions. Extracted from <TACE-CU-2007-AK>

(3) It must also be admitted the fact that realistic novels can be seen as treacherous, for they pretend to mimic a world that, in fact, does not exist beyond the fiction of the written words. Extracted from $<$ SACE-UZ2012-ARJ>

To gain a better understanding of the distribution of certainty adverbs in three corpora, it might be useful to examine Figure 2.

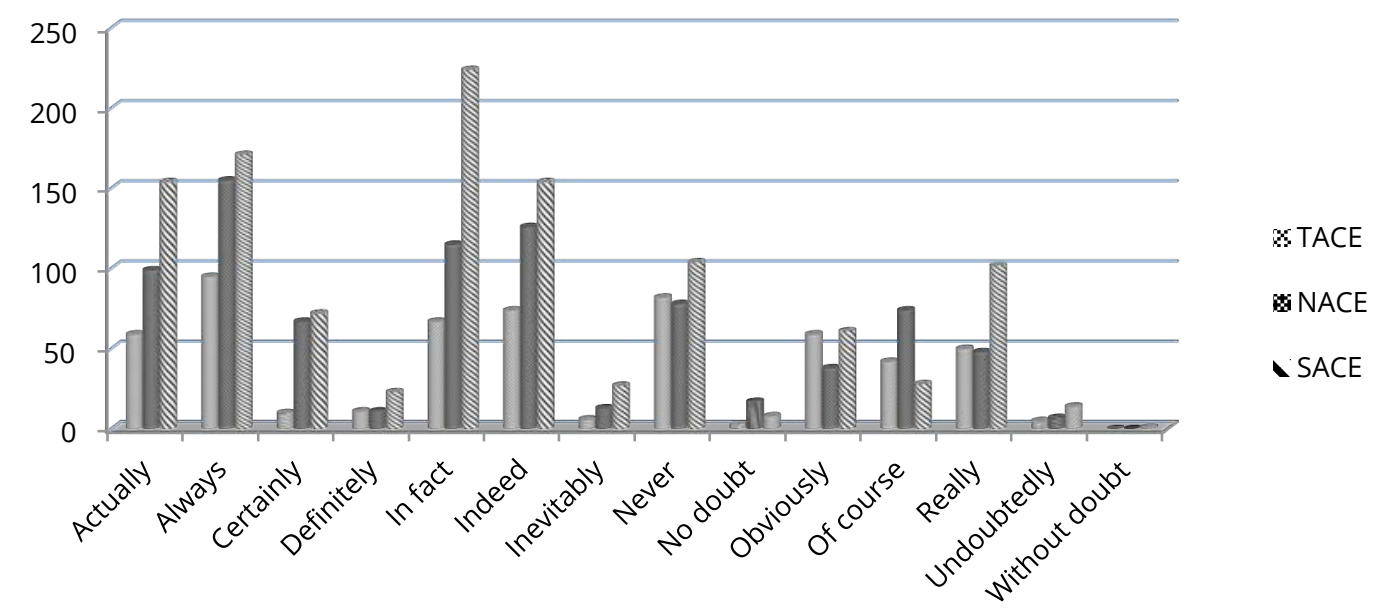

Figure 2. Certainty adverbs in three corpora.

Certainty adverb indeed, which revealed the second mostly used item following always in the native corpus, revealed the third more frequented item in both nonnative corpora. Three corpora also seem identical in the least found certainty adverb across them. Namely, without doubt, which was not found in NACE and TACE, occurred only once in SACE. However, the native corpus largely differs from the nonnative corpora in the use of no doubt, which was seen in it even more frequently than it was found across SACE and TACE in total. Always, certainly and indeed are the items NACE and SACE are relatively similar to each other in comparison to TACE. In return, NACE and TACE are more alike in the use of definitely and really when compared with SACE. Finally, the certainty adverbs obviously and of course were found at similar frequencies across the non-native corpora against the native corpus.

It is interesting to see that three corpora largely differ in the use of likelihood adverbs. They were, for instance, mostly used by NAEs (467 times) followed by SAEs 
(353 times) and TAEs (186 times), respectively. In other words, they were underused in both non-native corpora as opposed to the native corpus. Figure 4 illustrates the related distribution in three corpora.

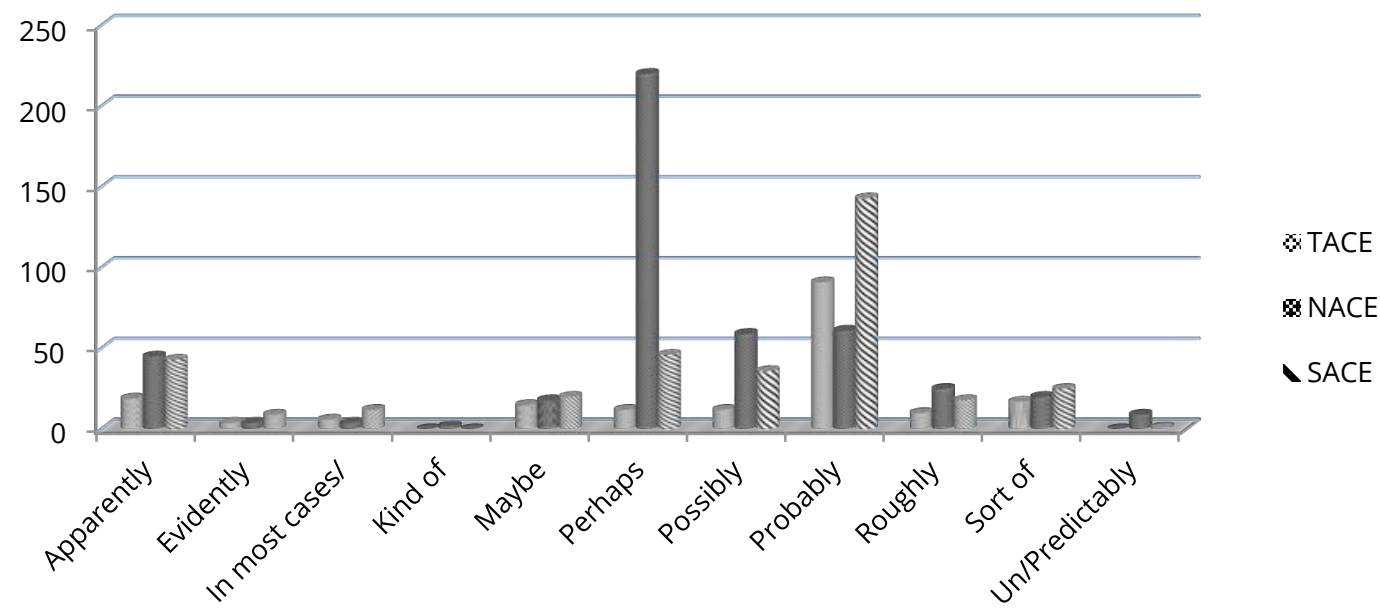

Figure 3. Likelihood adverbs in three corpora.

Figure 3 shows that there are remarkable differences among three corpora regarding the frequency distribution of likelihood adverbs except those of kind of, maybe and sort of. Despite being among the mostly used likelihood adverbs in all corpora, probably revealed the one they mostly differ from each other in its frequency; namely, it was seen 143 times in SACE, 91 times in TACE and 61 times in NACE. Likewise, perhaps, which constituted approximately half of the likelihood adverbs in NACE, appeared 220 times in it whereas it occurred only 46 times in SACE and 12 times in TACE. The following are the statements taken from a single work in NACE, across which perhaps was used 27 times.

As vocabulary knowledge grows it appears that a high PP advantage emerges, perhaps indicating that for 2 syllable words, the development of sub-lexical representations emerges later than for other prosodic structures in children with LI.

It is important to note however that this is the only probe where age related change in scores and hence perhaps improvement in overall processing capacity was evident.

One such trigger might be the development of phoneme-grapheme knowledge, which perhaps is less successful in the children with $\mathrm{LI}$ and so delays the switching process. Extracted from <NACE-NU-2009-CM>

Three corpora also differ in the use of possibly, which was underused in both nonnative corpora against the native corpus. However, they seem identical in the use of 
least used item throughout each. Kind of was employed twice in NACE and never found in the non-native corpora.

So far, frequency categories of epistemic adverbs in three corpora have been presented. In order to reveal whether the overuse and underuse values counted among the three corpora are statistically significant, a log likelihood test was administered to them. The following section provides the related test results.

\subsection{Log-likelihood results for epistemic adverbs in three corpora}

The first test was conducted between TACE and NACE regarding epistemic adverbs under the categories of certainty adverbs and likelihood adverbs. The results are provided in Table 6.

\begin{tabular}{|c|c|c|c|}
\hline Epistemic Adverbs & TACE (n) & NACE (n) & LL Ratio(* $p<0.05)$ \\
\hline Certainty & & & -59.50 \\
\hline Adverbs & 563 & 848 & \\
\hline Likelihood & & & -126.47 \\
\hline Adverbs & 186 & 467 & \\
\hline Total & 749 & 1315 & -160.26 \\
\hline
\end{tabular}

Table 6. LL Ratio of Epistemic Adverbs in TACE and NACE.

As can be seen in Table 6, adverbs in both categories were significantly underused by TAEs against NAEs, which was approved with -126.47 and -59.50 LL values for likelihood adverbs and certainty adverbs, respectively. The same analysis in concern was repeated between SACE and NACE and the results are displayed in Table 7.

\begin{tabular}{|c|c|c|c|}
\hline Epistemic Adverbs & SACE (n) & NACE (n) & LL Ratio( $\left.{ }^{*} p<0.05\right)$ \\
\hline Certainty Adverbs & 1143 & 848 & +273.77 \\
\hline Likelihood Adverbs & 353 & 467 & -15.36 \\
\hline Total & 1496 & 1315 & +12.55 \\
\hline
\end{tabular}

Table 7. LL Ratio of Epistemic Adverbs in SACE and NACE.

Table 7 shows that the epistemic adverbs were, in general, overused in SACE against NACE. Certainty adverbs were found 1143 times in SACE, and 848 times in NACE. That is, they were considerably overused by the non-native group against the native group, which was confirmed by +273.77 LL value. Likelihood adverbs, on the contrary, were underused in SACE against NACE. Yet, the statistical value measured 
between the two corpora in terms of likelihood adverbs was not found so high as the one calculated between the corpora in concern regarding certainty adverbs. As a last step, LL test was conducted on the frequencies of these adverbs used in TACE and those in SACE to see whether the observed differences between the two corpora are statistically significant. The related results can be seen in Table 8.

\begin{tabular}{lcrr}
\hline Epistemic Adverbs & TACE (n) & SACE (n) & LL Ratio(* $\mathbf{p}<\mathbf{0 . 0 5 )}$ \\
\hline Certainty Adverbs & 563 & 1143 & -207.10 \\
Likelihood Adverbs & 186 & 353 & -54.31 \\
\hline Total & 749 & 1496 & -261.0 \\
\hline n=raw frequency of epistemic adverbs in corpus & & \\
+ indicates overuse in TACE relative to SACE & & \\
- indicates underuse in TACE relative to SACE & &
\end{tabular}

Table 8. LL Ratio of Epistemic Adverbs in TACE and SACE.

As displayed in Table 8, epistemic adverbs were much more frequented in SACE in comparison to TACE, which was approved by a $-261.0 \mathrm{LL}$ value. It is also clear that both certainty and likelihood adverbs were underused by TAEs as opposed to SAEs. More specifically, certainty adverbs were employed by SAEs more than twice as many by TAEs. A similar case is approximately true for them in terms of likelihood adverbs. Namely, they occurred 353 times in SACE while they were seen 186 times in TACE. Both results were approved by LL results $(p<0.05)$.

\section{Conclusion}

In this study, epistemic adverbs in doctoral dissertations produced by TAEs (TurkishSpeaking Academic Authors of English), NAEs (Native Academic Authors of English) and SAEs (Academic Authors of English) were scrutinised using a quantitative analysis method. Overall, it has been revealed that each type was found at least once in three corpora. This section covers the evaluation of the research questions, implications to language teaching and a few suggestions for further research.

\subsection{Evaluation of Research Questions}

Our first research question investigated whether TAEs and NAEs significantly differ in the use of epistemic adverbs. The findings have indicated that TAEs used these items less frequently than NAEs, which was confirmed with the results of statistical analysis $(p<0.05)$. In parallel with this, an underuse was observed in TACE against NACE with respect to both certainty and likelihood adverbs, which was also confirmed by statistical results, leading us to the conclusion that TAEs are less certain than NAEs in conveying their stance to the readers. This might be attributed to socio-cultural construction of the community the non-native authors were born 
and raised in moving from Hyland (2006) who asserts 'tentativeness and reluctance to display an authoritative persona among Asian writers may, in part, be a product of a culturally and socially constructed view of self which makes assertion difficult'.

The second question was intended to find out whether SAEs and NAEs significantly differ regarding the use of these adverbs. The frequency analysis has shown that epistemic adverbs were overused in SACE as opposed to NACE. However, this does not necessarily mean that adverbs in both categories were employed by SAEs more frequently than NAEs. Specifically, certainty adverbs revealed to be significantly overused, and likelihood adverbs were slightly underused by SAEs against NAEs. Even though the statistical results have approved both findings, it is noteworthy that the difference between the two corpora in terms of likelihood adverbs is not so significant as the one concerning the likelihood adverbs, suggesting that SAEs are more assertive than NAEs in their academic writing.

The third question was posed to see whether TAEs and SAEs significantly differ in the use of epistemic adverbs. Both certainty and likelihood adverbs were significantly underused by TAEs against SAEs, indicating that the latter are more confident than the former while conveying their position.

\subsection{Implications to Language Teaching}

The study has revealed that certainty adverbs were mostly used by SAEs, and likelihood adverbs by NAEs, which leads us to the conclusion that SAEs are more confident than NAEs and TAEs and that NAEs are more tentative than TAEs and SAEs in their academic writing. That is, the native group has a stronger tendency to use cautious expressions in conveying their points when compared to the non-native groups. At this point, Wierzbicka (2006, p. 251) suggests 'an adequate semantic analysis of epistemic adverbs, which could really explain their meaning to students and teachers of English across the world, as well as for understanding modern Anglo culture'. For effective teaching of English, she suggests it should not be 'totally separated from its cultural traditions, and its areas of cultural elaboration and special cultural emphasis need to be recognized, elucidated, and examined in their historical and social context' (Wierzbicka, 2006, p. 251). According to Hyland (2002, p. 1111), teachers need 'to be aware of how academic conventions position students and be sensitive to the struggles of novice writers seeking to reconcile the discursive identities of their home and disciplinary cultures'. In addition, he posits that they should ensure the students are aware of 'the rhetorical options available to them and the effects of manipulating these options for interactional purposes' so that 'they will be better able to gain control over their writing and meet the challenges of participating in academic genres in a second language' (Ibid).In this vein, particularly 
those who teach academic writing to graduate students might be suggested to come up with some recommendations that will help them improve their academic writing skills. For instance, graduate students in our case, especially those who attend degree programmes in social sciences, should be clarified the principle that academic writing essentially requires using likelihood expressions rather than certainty ones in taking a position. In other words, they might be advised to be cautious while conveying their points and interpreting the findings of their research. Alternatively, they might be suggested to assign the students to examine a couple of articles published in one of the scholarly journals in the scope of social sciences concerning author stance (or a more specific point identified by the instructor), and to rewrite one of their earlier reports/ research papers by taking the outcomes of the assignment into consideration.

\subsection{Suggestions for Further Research}

The present study is limited to the investigation of doctoral dissertations produced by Turkish-speaking, Spanish-speaking and native academic authors of English between 2005 and 2012. It is also limited to the field of English Language Teaching, English Language and Literature, Applied Linguistics and Modern Languages. To attain more generalizable results, a further study might be conducted on corpora compiling from research papers/ dissertations written by scholars with other L1 background in various disciplines. The study might also be furthered to investigate stance in the spoken productions of native and non-native speakers of English in a range of academic settings such as classrooms, symposiums, and workshops. As our study is mostly concerned with the stance in the dissertations written by the graduate students in their second language, the results reported here regarding their stance might be somehow ambiguous. So, further research might be carried out on the corpora comprising research papers/ dissertations written in academic authors' first language.

\section{About the author}

Reyhan Ağçam received her MA and PhD in ELT from Çukurova University, Turkey. She currently works as an assistant professor at Faculty of Education, Kahramanmaraş Süt.ü İmam University, Turkey. Her research interests include language teaching, second language acquisition, academic writing and corpus linguistics. 


\section{Article history}

Paper received: 30 th October 2014

Paper received in revised form and accepted for publication: 21st July 2015

\section{References}

Adams, H. \& Quintana-Toledo, E. (2013). Adverbial stance marking in the introduction and conclusion sections of legal research articles". Revista de lingüística y lenguas aplicadas 8 , 13-22.

Alonso-Almeida, F. (2012). Sentential evidential adverbs and authorial stance in a corpus of English computing articles. RESLA. Revista española de lingüística aplicada, 25(1), 15-31.

Biber, D., Johanson, S, Leech, G., Conrad, S., \& Finegan, E. (1999). Longman grammar of spoken and written English. London: Longman.

Biber, D. (2006). University language: A corpus-based study of spoken and written registers. Amsterdam: John Benjamins.

Can, C. (2012). Uluslararası Tưrköğrenici İngilizcesi derleminde tutum belirteçleri. Dilbilim Araştırmaları, 1, 39-53.

Conrad, S, \& Biber, D. (2000). Adverbial making of Stance in Speech and Writing". In S. Hunston \& G. Thompson (Eds.), Evaluation in text (pp. 56-73). Oxford: Oxford University Press.

Granger, S. (1996). From CA to CIA and back: An integrated approach to computerized bilingual and learner corpora. In K. Aijmer, B. Altenberg, \& M. Johansson (Eds.), Languages in contrast (pp. 37-51). Lund: Lund University Press.

Hyland, K. (2002). Authority and invisibility: authorial identity in academic writing. Journal of Pragmatics, 34, 1091-1112.

Hyland, Ken. (2005). Stance and engagement: A model of Interaction in Academic Discourse. Discourse Studies, 7(2), 173-192.

Kotrč, M. (2012). Adverbials in the language of the press. Bachelor Thesis, Masaryk University.

Molina, S. (2012). Nonverbal markers of modality and evidentiality in MarENG. Revista de lenguas para fines específicos, 18, 45-70.

Rozumko, A. (2008). An interdisciplinary approach to teaching grammar to prospective teachers of English. In K. Bogacki, B. Głowacka, \& D. Potocka (Eds.), Interdisciplinary perspectives in foreign language teacher education (pp. 309-318). Białystok: Wydawnictwo Uniwersytetu w Białymstoku.

Rozumko, A. (2012). Speech-act adverbs in English and Polish: A cross-linguistic and crosscultural comparison. Białostockie Archiwum Językowe, 12, 183-196. 
Scollon, R. (1994). As a matter of fact: the changing ideology of authorship and responsibility in discourse. World Englishes, 13, 34-46.

Scott, M. (2012). WordSmith tools, v. 6. Liverpool: Lexical Analysis Software.

Wierzbicka, A. (2006). English: Meaning and culture. Oxford: Oxford University Press. 